\title{
Information Transmission of Volatility between WTI and Brent Crude Oil Markets ${ }^{\dagger}$
}

\author{
Sang Hoon Kang* and Seong-Min Yoon**
}

ABSTRACT : Transmission mechanisms of volatility between two crude oil markets (WTI and Brent markets) have drawn the attention of numerous academics and practitioners because they both play crucial roles in portfolio and risk management in crude oil markets. In this context, we examined the volatility linkages between two representative crude oil markets using a VECM and an asymmetric bivariate GARCH model. First, looking at the return transmission through the VECM test, we found a long-run equilibrium and bidirectional relationship between two crude oil markets. However, the estimation results of the GARCH-BEKK model suggest that there is unidirectional volatility spillover from the WTI market to the Brent market, implying that the WTI market tends to exert influence over the Brent market and not vice versa. Regarding asymmetric volatility transmission, we also found that bad news volatility in the WTI market increases the volatility of the Brent market. Thus, WTI information is transmitted into the Brent market, indicating that the prices of the WTI market seem to lead the prices of the Brent market.

Keywords : Asymmetric volatility transmission, Causality, Cointegration, GARCH-BEKK model, Volatility spillover effect

JEL 분류: C32, C58, G14, G17, Q47

Received: July 30, 2013. Revised: November 15, 2013. Accepted: November 20, 2013.

$+\quad$ This work was supported by the National Research Foundation of Korea Grant, funded by the Korean Government (NRF-2011-330-B00044). The authors would like to thank participants of the 2012 Zagreb International European Academic Conference for their helpful suggestions.

* Department of Business Administration, Pusan National University, Jangjeon2-Dong, Geumjeong-Gu, Busan, 609-735, Korea(e-mail: sanghoonkang@pusan.ac.kr)

** Department of Economics, Pusan National University, Jangjeon2-Dong, Geumjeong-Gu, Busan, 609-735, Korea, Corresponding author(e-mail: smyoon@pusan.ac.kr) 


\section{Introduction}

In recent years, crude oil prices have reached record highs, and rising oil prices have posed a new threat to the global economy. Both academicians and energy market participants have focused on forecasting and modeling oil prices by quantifying and managing the risks inherent in their frequent volatilities. In particular, the information transmission of crude oil prices has drawn the attention of numerous academics and practitioners as crude oil prices play a prominent role in national economies.

Rising crude oil fluctuations affect the world economy in many different and significant ways. For example, rising crude oil prices increase the production costs of goods and services and the costs of transportation and heating. Thus, consumers, governments and practitioners are greatly concerned about the volatility of crude oil prices and its possible negative economic effects, such as those on business cycles (Mork, 1994), macroeconomies (Lee, Lee and Ratti, 2001; Rafiq, Salim and Bloch, 2009), and inflation (Hooker, 2002; Hamilton and Herrera, 2004)1).

In addition, the information transmission between crude oil markets and other financial markets is becoming of greater interest to portfolio managers and policy makers because of the increasing trend of globalization. Many empirical studies have examined the interaction between the crude oil markets and other financial markets such as energy markets (Ewing, Malik and Ozfidan, 2002), stock markets (Sadorsky, 1999, 2001, 2012; Malik and Hammoudeh, 2007; Aloui and Jammazi, 2009; Chiou and Lee, 2009), bond market (Seo, 2009), futures markets (Bekiros and Diks, 2008; Kaufmann and Ullman, 2009), and exchange rate markets (Sadorsky, 2000; Zhang et al., 2008). These studies have found evidence of significant return and volatility spillovers between crude oil markets and other financial markets.

1) Investors are interested in risk management. For investment risk of crude oil market, see Kang and Yoon (2007). 
In contrast, this study investigated the information transmission mechanism between two crude oil prices: WTI (West Texas Intermediate) and Brent (Brent Blend). ${ }^{2)}$ We began the research with a question: Does one market lead the other in terms of information transmission? The existence of the spillover effect implies that one large shock increases prices not only in its own asset or market but also in other assets or markets. In particular, price volatility is often related to the rate of information flow (Ross, 1989). If information comes in clusters, prices may exhibit volatility even if the market perfectly and instantaneously adjusts to the news. Thus, studies on volatility spillover can help us understand how information is transmitted across crude oil markets.

The main contributions of this paper are twofold. First, this study focuses on the return causality relationship between WTI and Brent oil prices by employing the vector error correction model (VECM) ${ }^{3}$. This allows us to analyze both the longand short-run lead-lag relationship between crude oil prices. Second, this study examines the casual direction of volatility spillover using both symmetric and asymmetric bivariate GARCH models. In particular, we explore whether bad news in one market leads to a larger volatility in the other market than does good news. A good understanding of the asymmetric volatility response to news is an important ingredient for designing hedging strategies and optimizing portfolios.

The rest of this paper is organized as follows. Section 2 presents the econometric methodology. Section 3 provides descriptive statistics of the sample data. Section 4 discusses the empirical results. Section 5 presents our conclusions.

2) WTI is the base grade traded, as "light sweet crude," on the New York Mercantile Exchange (NYEMX), while Brent is traded on London's International Petroleum Exchange (IPE).

3) Kim, Heo and Kim (2007) used VECM to analyze regionalization of the world crude oil markets. Kang and Yoon (2010) also used VECM to investigate relationship between the returns and the volatility of crude oil prices. 


\section{Methodology}

\section{Cointegration Test}

Cointegration is an econometric property of time series variables. If two or more series are themselves non-stationary but a linear combination of them is stationary, then the series are said to be cointegrated. In practice, cointegration is a means of correctly testing those hypotheses concerning the relationship between two variables having unit roots. In the literature, the Johansen (1991) cointegration test is the most popular approach for testing cointegration. This cointegration test is based on maximum likelihood estimators of a vector auto regressive (VAR) process, and the likelihood ratio test statistic for the hypothesis of the at most $r$ cointegrated relationship and at least $m=n-r$ common trend is given by

$$
\begin{aligned}
& \lambda_{\text {trace }}(r)=-T \sum_{i=r+1}^{n} \ln \left(1-\widehat{\lambda_{i}}\right), \\
& \lambda_{\max }(r, r+1)=-T \ln \left(1-\widehat{\lambda_{r+i}}\right),
\end{aligned}
$$

where $\lambda_{\text {trace }}(r)$ is the trace statistic, $\lambda_{\max }(r, r+1)$ is the eigen-max statistics, $\hat{\lambda_{i}}$ denotes the estimated eigenvalue, and $T$ is the sample size. The null hypothesis tested in $\lambda_{\text {trace }}(r)$ is no cointegration. In fact, for bivariate cointegration tests, up to two null hypotheses can be tested. If the null hypothesis that $r=0$ is rejected, at least one cointegrating vector may exist and the second hypothesis that $r \leq 1$ is subsequently tested.

\section{VECM}

The term "cointegration" implies that causality exists between the two series; however, it does not specify the direction of the causal relationship. If cointegration 
exists between the variables, then we can rule out the possibility of a spurious correlation. Thus, in this context, we have employed the VECM to detect the direction of the causality. The VECM distinguishes between long- and short-term relationships between the variables and can identify causation sources that cannot be detected by the usual Granger causality test (Belloumi, 2009).

In this study, the VECM for the WTI $\left(x_{t}\right)$ and Brent $\left(y_{t}\right)$ series can be written in the following manner:

$$
\begin{aligned}
& \triangle x_{t}=\beta_{x, 0}+\gamma_{x} e c_{t-1}+\Sigma_{j=1}^{2} \beta_{x x, j} \Delta x_{t-j}+\Sigma_{j=1}^{2} \beta_{x y, j} \Delta y_{t-j}+\varepsilon_{x, t}, \\
& \triangle y_{t}=\beta_{y, 0}+\gamma_{y} e c_{t-1}+\Sigma_{j=1}^{2} \beta_{y x, j} \Delta x_{t-j}+\Sigma_{j=1}^{2} \beta_{y y, j} \Delta y_{t-j}+\varepsilon_{y, t},
\end{aligned}
$$

where $\Delta x_{t}$ and $\Delta y_{t}$ represent the first differences between these variables and capture their short-run disturbances; $e c_{t-1}$ is the error correction term derived from the long-run cointegration relationship and measures the magnitude of the past disequilibrium (i.e., residuals). The error correction coefficients, $\gamma_{x}$ and $\gamma_{y}$, represent the deviation of the dependent variables from the long-run equilibrium, and $\gamma_{x}$ and/or $\gamma_{y}$ should be significantly different from zero if the two variables are cointegrated.

By using the coefficients of each explanatory variable, we can test their short-run causal relationships. For example, if the coefficients $\beta_{x y, j}\left(\beta_{y x, j}\right)$ are significant, then we can explain $\Delta x_{t}\left(\Delta y_{t}\right)$ using $\Delta y_{t-j}\left(\Delta x_{t-j}\right)$; in other words, we can explain the causality relationship between the two crude oil markets. Finally, we can use the coefficients of $\beta_{x x, j}$ and $\beta_{y y, j}$ to measure how the returns of the two markets react to their own lagged values, which implies the degree of meanreverting behavior from both time series.

\section{Bivariate GARCH Model}

Much attention has focused on how news from one market affects the volatility 
process of the other. In this study, we analyze the volatility spillovers effect between the two crude oil markets by using a bivariate framework of the BEKK parameterization (Engle and Kroner, 1995). In this model, the variance-covariance matrix of equations depends on the squares and cross products of innovation $\varepsilon_{t}$, which is derived from the following mean equation:

$$
R_{t}=\mu_{t}+\varepsilon_{t}, \varepsilon_{t} \mid \Omega_{t-1} \sim N\left(0, H_{t}\right),
$$

where $R_{t}$ is the $2 \times 1$ vector of returns at time $t$ for each market. The $2 \times 1$ vector of random errors, $\varepsilon_{t}$, represents the innovation for each market at time $t$ with its corresponding $2 \times 2$ conditional variance-covariance matrix $H_{t}$. The market information available at time $t-1$ is represented by $\Omega_{t-1}$.

This bivariate structure thus facilitates the measurement of the effects of innovations in the mean returns of one market on its own lagged returns and those of the lagged returns of the other market. The standard BEKK parameterization for the bivariate GARCH model is written as:

$$
H_{t}=C^{\prime} C+A^{\prime} \varepsilon_{t-1} \varepsilon^{\prime}{ }_{t-1} A+B^{\prime} H_{t-1} B,
$$

where $H_{t}$ is a $2 \times 2$ matrix of conditional variance-covariance at time $t$, and $C$ is a $2 \times 2$ lower triangular matrix with three parameters. $A$ is a $2 \times 2$ square matrix of coefficients and measures the extent to which conditional variances are correlated past squared errors. $B$ is a $2 \times 2$ squared matrix of coefficients and shows the extent to which current levels of conditional variances are related to past conditional variances. 


$$
\begin{aligned}
{\left[\begin{array}{ll}
h_{11, t} & h_{12, t} \\
h_{21, t} & h_{22, t}
\end{array}\right]=} & {\left[\begin{array}{ll}
c_{11} & \\
c_{21} & c_{22}
\end{array}\right]^{\prime}\left[\begin{array}{ll}
c_{11} & \\
c_{21} & c_{22}
\end{array}\right] } \\
& +\left[\begin{array}{ll}
a_{11} & a_{12} \\
a_{21} & a_{22}
\end{array}\right]^{\prime}\left[\begin{array}{cc}
\varepsilon_{1, t-1}^{2} & \varepsilon_{1, t-1} \varepsilon_{2, t-1} \\
\varepsilon_{2, t-1} \varepsilon_{1, t-1} & \varepsilon_{2, t-1}^{2}
\end{array}\right]\left[\begin{array}{ll}
a_{11} & a_{12} \\
a_{21} & a_{22}
\end{array}\right] \\
& +\left[\begin{array}{ll}
b_{11} & b_{12} \\
b_{21} & b_{22}
\end{array}\right]^{\prime}\left[\begin{array}{ll}
h_{11, t-1} & h_{12, t-1} \\
h_{21, t-1} & h_{22, t-1}
\end{array}\right]\left[\begin{array}{ll}
b_{11} & b_{12} \\
b_{21} & b_{22}
\end{array}\right],
\end{aligned}
$$

where $h_{11, t}$ denotes the variance of the market returns, $h_{12, t}$ denotes the covariance of the WTI returns and the Brent returns, and $h_{22, t}$ denotes the variance of the Brent returns. The significance of diagonal coefficients $a_{11}\left(a_{22}\right)$ suggests that the current conditional variance of $h_{11, t}\left(h_{22, t}\right)$ is correlated with its own past squared errors, while the significance of lagged variance $b_{11}\left(b_{22}\right)$ indicates that the current conditional variance of $h_{11, t}\left(h_{22, t}\right)$ is affected by its own past conditional variance. In addition, the significance of the off-diagonal coefficients $a_{12}$ and $b_{12}$ indicates a volatility spillover effect from the WTI market to the Brent market, whereas the significance of off-diagonal coefficients $a_{21}$ and $b_{21}$ suggests a volatility spillover effect from the Brent market to the WTI market.

The standard BEKK model implies that only the magnitude of past return innovations is important in determining current conditional variances and covariances. However, it has been well observed that volatility responds asymmetrically to positive and negative innovations of equal magnitude: volatility tends to rise higher in response to negative shocks, such as bad news, than to positive shocks, such as good news (Engle and Ng, 1993; Glosten, Jagannathan and Runkle, 1993; Kroner and Ng, 1998).

To circumvent this problem, Kroner and Ng (1998) extended the GJR-GARCH approach to a multivariate setting that can capture the asymmetric response to news on volatility. The asymmetric BEKK model is written as:

$$
H_{t}=C^{\prime} C+A^{\prime} \varepsilon_{t-1} \varepsilon^{\prime}{ }_{t-1} A+B^{\prime} H_{t-1} B+D^{\prime} \eta_{t-1} \eta^{\prime} D
$$




$$
\begin{aligned}
{\left[\begin{array}{ll}
h_{11, t} & h_{12, t} \\
h_{21, t} & h_{22, t}
\end{array}\right]=} & {\left[\begin{array}{ll}
c_{11} & \\
c_{21} & c_{22}
\end{array}\right]^{\prime}\left[\begin{array}{ll}
c_{11} & \\
c_{21} & c_{22}
\end{array}\right] } \\
& +\left[\begin{array}{ll}
a_{11} & a_{12} \\
a_{21} & a_{22}
\end{array}\right]^{\prime}\left[\begin{array}{cc}
\varepsilon_{1, t-1}^{2} & \varepsilon_{1, t-1} \varepsilon_{2, t-1} \\
\varepsilon_{2, t-1} \varepsilon_{1, t-1} & \varepsilon_{2, t-1}^{2}
\end{array}\right]\left[\begin{array}{ll}
a_{11} & a_{12} \\
a_{21} & a_{22}
\end{array}\right] \\
& +\left[\begin{array}{ll}
b_{11} & b_{12} \\
b_{21} & b_{22}
\end{array}\right]^{\prime}\left[\begin{array}{ll}
h_{11, t-1} & h_{12, t-1} \\
h_{21, t-1} & h_{22, t-1}
\end{array}\right]\left[\begin{array}{ll}
b_{11} & b_{12} \\
b_{21} & b_{22}
\end{array}\right] \\
& +\left[\begin{array}{ll}
d_{11} & d_{12} \\
d_{21} & d_{22}
\end{array}\right]^{\prime}\left[\begin{array}{ll}
\eta_{1, t-1}^{2} & \eta_{1, t-1} \eta_{2, t-1} \\
\eta_{2, t-1} & \eta_{2, t-1}^{2}
\end{array}\right]\left[\begin{array}{ll}
d_{11} & d_{12} \\
d_{21} & d_{22}
\end{array}\right]
\end{aligned}
$$

where $\eta_{t-1}=\left[\frac{\max \left(0,-\varepsilon_{1, t-1}\right)}{\max \left(0,-\varepsilon_{2, t-1}\right)}\right], D$ is a $2 \times 2$ squared matrix of parameters and captures any asymmetry in variances and covariance through the definition of $\eta_{t-1}$. If the off-diagonal coefficient $d_{12}\left(d_{21}\right)$ is positive and significant, the bad news volatility of the WTI market (or the Brent market) causes a higher volatility of the Brent (or the WTI market) than the good news volatility of the WTI market (or the Brent market).

The parameters of the bivariate GARCH model can be estimated by the maximum likelihood estimation method optimized with the Berndt, Hall, Hall and Hausman $(\mathrm{BHHH})$ algorithm. The conditional $\log$ likelihood function $L(\theta)$ is expressed as:

$$
L(\theta)=-T \log 2 \pi-0.5 \sum_{t=1}^{T} \log \left|H_{t}(\theta)\right|-0.5 \sum_{t=1}^{T} \varepsilon_{t}(\theta)^{\prime} H_{t}^{-1} \varepsilon_{t}(\theta),
$$

where $T$ is the number of observations and $\theta$ denotes the vector of all the unknown parameters.

\section{Data and Descriptive Statistics}

This study analyzes the information transmission between the crude markets. To do this, we consider two representative crude oil prices, the WTI and Brent prices ${ }^{4}$.

4) There are three benchmark crude oil prices; WTI, Brent and Dubai. This study only chooses two of them because both the WTI and Brent prices are more often traded in energy markets. 
The data sets consist of the weekly Friday closing prices spanning January 5, 1990 to August 26, 2011 (a total of 1,130 observations) provided by the US Energy Information Administration (EIA) $)^{5}$. Figure 1 shows the dynamics of the two sets of oil price data.

The spot prices of crude oil have been influenced by events with economic and geo-political effects. For example, (1) the First Gulf war in 1990-91 collapsed oil production, resulting in the doubling of the price of crude oil; (2) oil prices went down in 1997-98 owing to the Asian currency crisis; (3) Organization of Petroleum Export Countries (OPEC) curtailed the production of crude oil by 4.2 million barrels per day between 2000 and 2001, resulting in increased crude oil prices; (4) the uncertainties associated with the 9/11 terror attack in 2001 and the subsequent US military action in Iraq beginning in March 2003 reversed the trend in oil prices; (5) crude oil prices rose owing to global economic growth, growing demand, and stagnant supply in 200407; (6) crude oil prices experienced their biggest decrease owing to the US recession in 2007-08; (7) current oil prices have rebounded up to $\$ 120$ owing to concerns about the political unrest in the Northern Africa region and the European debt crisis.

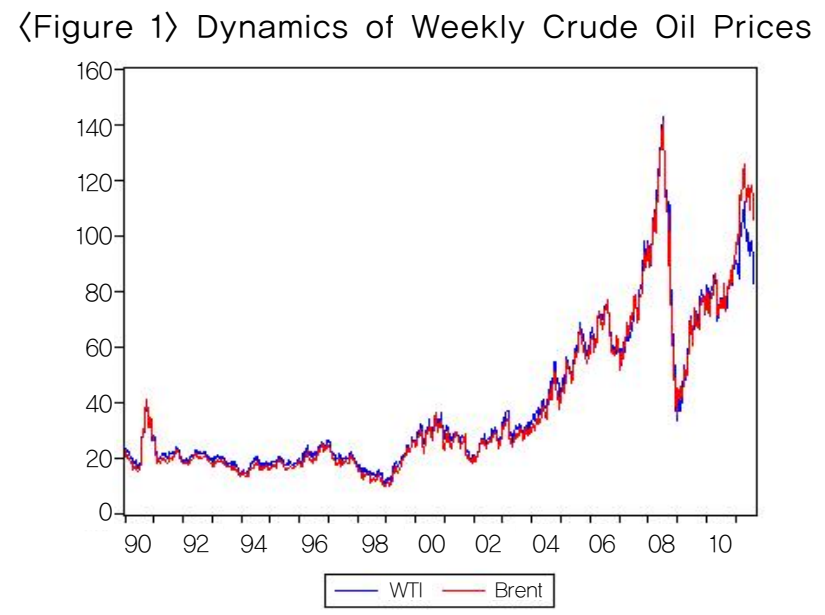

5) We consider the impact of recent price fluctuations during the period of 2006-2011. 
The return series of the two prices are computed by $R_{i, t}=\ln \left(p_{i, t} / p_{i, t-1}\right) \times 100$ for $t=1,2, \cdots, T$, where $R_{i, t}$ denotes the continuously compounded returns for indices $i$ at time $t$, and $p_{i, t}$ denotes the closing price of indices $i$ at time $t$. The two return series clearly show volatility clustering in Figure 2.

〈Figure 2〉 Weekly Returns for Crude Oil Prices
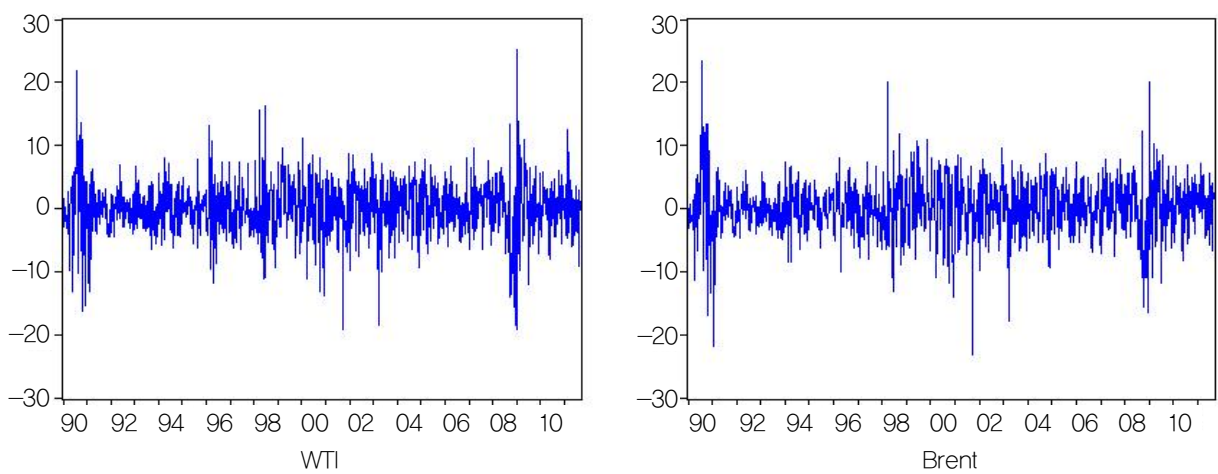

Table 1 shows the descriptive statistics for the two return series. The sample mean of returns is very small, and the corresponding standard deviations of returns are much higher. The distribution of returns is not normally distributed, as is indicated by the skewness, kurtosis and Jarque-Bera test. In addition, the null hypothesis of no serial correlation is statistically rejected at the $1 \%$ significance level by the Ljung-Box test statistic, $L B^{2}(32)$, with a lag of 32 for the squared return series, implying that the squared returns exhibit significant signs of serial correlation. These results are in favor of a model that incorporates ARCH/GARCH features. 
$\langle$ Table 1〉 Descriptive Statistics of Sample Returns

\begin{tabular}{c|c|c}
\hline Statistics & WTI & Brent \\
\hline Mean & 0.115 & 0.141 \\
\hline Std. Dev. & 4.422 & 4.403 \\
\hline Skewness & -0.199 & -0.270 \\
\hline Kurtosis & 5.991 & 5.971 \\
\hline Jarque-Bera (J-B) & $428.81^{* * *}$ & $429.49^{* * *}$ \\
\hline$L B^{2}(32)$ & $616.63^{* * *}$ & $411.21^{* * *}$ \\
\hline
\end{tabular}

Notes: The J-B corresponds to the test statistic for the null hypothesis of normality in sample returns distribution. The Ljung-Box statistic, $L B^{2}(32)$, checks for the serial correlation of the squared returns up to the $32^{\text {nd }}$ order. $* * *$ indicates the rejection of the null hypothesis at the $1 \%$ significance level.

Table 2 provides the results of augmented Dickey-Fuller (ADF) and PhillipsPerron (PP) unit root tests for the log price series and the return series. The null hypothesis of the ADF and PP tests is that a time series contains a unit root. As shown in Table 2, the calculated values of both the ADF and PP test statistic indicate that the $\log$ price series contain a single unit root at the $1 \%$ significance level, implying that the log prices series are non-stationary. However, in the case of return series, both these statistics reject the null hypothesis of a unit root at the $1 \%$ significance level, implying that the return series are stationary in all samples.

〈Table 2〉 Results of Unit Root Test for Log Price and Returns

\begin{tabular}{c|c|c|c|c}
\hline & WTI & & Brent & \\
\hline & Log Price & Returns & Log Price & Returns \\
\hline ADF [prob.] & $-1.017[0.745]$ & $-17.52[0.000]$ & $-0.698[0.845]$ & $-27.98[0.000]$ \\
\hline PP [prob.] & $-0.973[0.764]$ & $-30.43[0.000]$ & $-0.706[0.843]$ & $-27.98[0.000]$ \\
\hline
\end{tabular}

Note: MacKinnon's (1991) 1\% critical value is -3.435 for the ADF and PP tests. 


\section{Empirical Results}

\section{Results of Cointegration Test and Causality Test}

Table 3 shows the results of the Johansen cointegration test for the WTI and Brent return series. The trace statistic is 35.22 , which is above the $5 \%$ critical value of 15.49 , rejecting the null hypothesis of no cointegration between WTI and Brent series variables, $H_{0}: r=0$ at the $5 \%$ significance level. Likewise, the max-eigen statistic is 34.60 , which rejects the null hypothesis of no cointegration at the $5 \%$ significance level. However, under $H_{0}: r \leq 1$, the trace and max-eigen statistics are equal to 0.614 , which are below the $5 \%$ critical value of 3.841 . Thus, in this case, we must accept the null hypothesis of one cointegration at the $5 \%$ significance level. As a result, we have found at least one cointegration relationship between the WTI and Brent series. In other words, we have found evidence of a long-run relationship between the two series.

〈Table 3〉Results of Johansen Cointegration Test

\begin{tabular}{c|c|c|c|c}
\hline Null Hypothesis & Trace Statistic & 0.05 Critical Value & Max-Eigen Statistic & 0.05 Critical Value \\
\hline$r=0$ & $35.22^{* *}$ & 15.49 & $34.60^{* *}$ & 14.28 \\
\hline$r \leq 1$ & 0.614 & 3.841 & 0.614 & 3.841 \\
\hline
\end{tabular}

Notes: $* *$ denotes rejection of the hypothesis at the $5 \%$ significance level. The reported critical values are the Osterwald-Lenum (1992) critical values.

Furthermore, we investigated the short- and long-run causality using the VECM. Table 4 summarizes the estimation results of the VECM obtained from Equations (3) and (4). According to the long-run relationship using $e c_{t-1}$ (an error correction term), only the estimated coefficient $e c_{t-1}$ for the WTI series is statistically significant at the $1 \%$ level, suggesting that the Brent crude oil price is less likely to adjust than the WTI crude oil price when the two crude oil markets deviate from their long-term cointegration relationship. Furthermore, we consider short-run 
causality between the WTI and Brent series. Most of the transmission coefficients $\left(\beta_{x y, 1}, \beta_{x y, 2}\right.$, and $\left.\beta_{y x, 2}\right)$ are statistically significant, implying a bi-directional relationship between the WTI and Brent return series. This evidence indicates that the WTI returns have an impact on the Brent returns and vice versa.

〈Table 4〉 Estimation Results of the VECM

\begin{tabular}{c|cccccc}
\hline \multirow{2}{*}{ Model } & \multicolumn{5}{|c}{$\Delta x_{t}=\beta_{x, 0}+\gamma_{x} e c_{t-1}+\Sigma_{j=1}^{2} \beta_{x x, j} \Delta x_{t-j}+\Sigma_{j=1}^{2} \beta_{x y, j} \Delta y_{t-j}+\varepsilon_{x, t}$} \\
& \multicolumn{4}{|c}{$\Delta y_{t}=\beta_{y, 0}+\gamma_{y} e c_{t-1}+\Sigma_{j=1}^{2} \beta_{y x, j} \Delta x_{t-j}+\sum_{j=1}^{2} \beta_{y y, j} \Delta y_{t-j}+\varepsilon_{y, t}$} \\
\hline \hline$\Delta x_{t}$ & $\beta_{x, 0}$ & $\gamma_{x}$ & $\beta_{x x, 1}$ & $\beta_{x x, 2}$ & $\beta_{x y, 1}$ & $\beta_{x y, 2}$ \\
\hline & 0.000 & -0.068 & 0.016 & -0.364 & 0.163 & -0.145 \\
& $(0.001)$ & $(0.033)^{* *}$ & $(0.056)$ & $(0.056)^{* * *}$ & $(0.056)^{* * *}$ & $(0.055)^{* * *}$ \\
\hline$\triangle y_{t}$ & $\beta_{y, 0}$ & $\gamma_{y}$ & $\beta_{y x, 1}$ & $\beta_{y x, 2}$ & $\beta_{y y, 1}$ & $\beta_{y y, 2}$ \\
\hline & 0.001 & 0.040 & 0.051 & 0.139 & 0.108 & 0.343 \\
& $(0.001)$ & $(0.033)$ & $(0.057)$ & $(0.055)^{* * *}$ & $(0.057)$ & $(0.055)^{* * *}$ \\
\hline
\end{tabular}

Note: $* *$ and $* * *$ indicate significance at the $5 \%$ and $1 \%$ levels, respectively.

\section{Volatility Spillover between the WTI and Brent Crude Oil Markets}

In order to examine the volatility spillover effect, we use the symmetric and asymmetric GARCH $(1,1)$ models based on the BEKK approach. The estimation results of the BEKK model are reported in Table 5. To check the accuracy of the model specifications, we employ two diagnostic tests: the LM ARCH statistic, $\mathrm{ARCH}_{i}(10)$, for standardized residuals; and the Ljung-Box statistic, $L B_{i}^{2}(32)$, for squared standardized residuals. Note that the $\mathrm{ARCH}_{i}(10)$ test statistic checks the remaining $\mathrm{ARCH}$ effect in standardized residuals and that the $L B_{i}^{2}(32)$ test statistic checks for the serial correlation of squared standardized residuals. The insignificance of $\mathrm{ARCH}_{i}(10)$ and $L B_{i}^{2}(32)$ statistics indicates the appropriateness of the symmetric and asymmetric GARCH-BEKK model.

The important coefficients in the bivariate GARCH model are $a_{i, i}$ and $b_{i, i}$ elements of matrices $A$ and $B$, where $i=1$ stands for WTI, and $i=2$, for Brent. As mentioned earlier, the diagonal elements in matrix $A$ capture the own past shock 
effect, while the diagonal elements in matrix $B$ measure the own past volatility effect. From Table 5, the diagonal parameters $\left(b_{11}\right.$ and $\left.b_{22}\right)$ in matrix $B$ are statistically significant, indicating the presence of strong GARCH effects; the own past volatility affects the conditional variance of both markets. Furthermore, the diagonal parameters $\left(a_{11}\right.$ and $\left.a_{22}\right)$ are significant, implying an $\mathrm{ARCH}$ effect in both markets.

〈Table 5〉 Estimation Results of the GARCH-BEKK Model

\begin{tabular}{|c|c|c|c|c|}
\hline & \multicolumn{2}{|c|}{ Symmetric } & \multicolumn{2}{|c|}{ Asymmetric } \\
\hline Coefficient & Estimates & Std. Error & Estimates & Std. Error \\
\hline \multicolumn{5}{|c|}{ Panel A: Symmetric and Asymmetric GARCH $(1,1)$-BEKK Estimations } \\
\hline$c_{11}$ & $1.092 * * *$ & $(0.143)$ & $0.991^{* * *}$ & (0.139) \\
\hline$c_{21}$ & $0.383 * * *$ & $(0.160)$ & $0.486^{* * *}$ & $(0.145)$ \\
\hline$c_{22}$ & 0.000 & $(0.260)$ & -0.000 & $(0.001)$ \\
\hline$a_{11}$ & $0.416^{* * *}$ & $(0.068)$ & $0.302 * * *$ & $(0.070)$ \\
\hline$a_{12}$ & $-0.156^{* * *}$ & $(0.067)$ & $-0.158 * * *$ & (0.064) \\
\hline$a_{21}$ & $-0.132 * * *$ & $(0.065)$ & -0.024 & $(0.075)$ \\
\hline$a_{22}$ & $0.366^{* * *}$ & $(0.059)$ & $0.385^{* * *}$ & $(0.060)$ \\
\hline$b_{11}$ & $0.862 * * *$ & $(0.051)$ & $0.909^{* * *}$ & $(0.045)$ \\
\hline$b_{12}$ & $0.104 * *$ & $(0.052)$ & $0.098^{* * *}$ & $(0.046)$ \\
\hline$b_{21}$ & 0.064 & $(0.045)$ & 0.011 & $(0.045)$ \\
\hline$b_{22}$ & $0.876^{* * *}$ & $(0.046)$ & $0.865^{* * *}$ & $(0.041)$ \\
\hline$d_{11}$ & & & $0.382 * * *$ & $(0.078)$ \\
\hline$d_{12}$ & & & $0.365^{* * *}$ & $(0.075)$ \\
\hline$d_{21}$ & & & -0.066 & $(0.066)$ \\
\hline$d_{22}$ & & & $0.242 * * *$ & $(0.093)$ \\
\hline
\end{tabular}

Panel B: Diagnostic Tests

\begin{tabular}{c|c|c}
$L B_{1}^{2}(32)$ & $28.71[0.633]$ & $25.29[0.793]$ \\
$L B_{2}^{2}(32)$ & $29.48[0.594]$ & $19.96[0.951]$ \\
$\mathrm{ARCH}_{1}(10)$ & $0.899[0.533]$ & $0.675[0.747]$ \\
$\mathrm{ARCH}_{2}(10)$ & $0.428[0.933]$ & $0.211[0.995]$ \\
$\log -$ likelihood & -5550.54 & -5520.58 \\
\hline
\end{tabular}

Notes: P-values are in brackets and standard errors are in parenthesis. The $\mathrm{ARCH}_{i}(10)$ test statistic checks the remaining ARCH effects in standardized residuals. The $L B_{i}^{2}(32)$ test statistic checks for the serial correlation of squared standardized residuals. $* *$ and $* * *$ indicate significance at the $5 \%$ and $1 \%$ levels, respectively.

The off-diagonal elements of matrices $A$ and $B$ capture cross-market effects, such as shock spillover and volatility spillover effects between the WTI and Brent markets. In the symmetric GARCH model, we find evidence of bidirectional shock 
spillover effect between two crude oil markets because the coefficients $a_{12}$ and $a_{21}$ are negatively significant at the $1 \%$ level. However, in the asymmetric GARCH model, there is a unidirectional shock spillover effect from the WTI market to the Brent market.

Furthermore, we identify a unidirectional volatility spillover from the WTI market to the Brent market in both the symmetric and asymmetric GARCH models. For example, the past volatility of the WTI market increases the present volatility of the Brent market owing to the positive value of the coefficient $b_{12}$, but the reverse direction is impossible. Thus, this evidence indicates that the WTI market appears to play a more important role in influencing the volatility of the Brent market.

As far as matrix $D$ is concerned, we find evidence of an asymmetric response to negative shocks (bad news) of the own market for both returns because of the significance of diagonal coefficients $d_{11}$ and $d_{22}$. This evidence suggests that the own negative shocks have more effect than the own positive shocks on the volatility of each market. In addition, the cross-market asymmetric response is evident from the WTI market to the Brent market, as the coefficient $d_{12}$ is positively significant at the $1 \%$ level. This means that bad news in the WTI market leads to a greater volatility change in the Brent market than does good news in the Brent market.

In summary, our empirical results show a unidirectional volatility spillover from the WTI market to the Brent market, indicating that WTI shocks heighten Brent market volatility but not vice versa. More importantly, bad shocks in the WTI market cause greater volatility in the Brent market than do good shocks in the WTI market, owing to the cross-market hedging demand. For example, a fall in WTI prices induces an active hedger to shift funds from the WTI market into the Brent market. Thus, bad news in the WTI market will increase volatility changes in the Brent market. 


\section{Conclusions}

This paper investigated the return and volatility spillover effects between two representative crude oil markets using the VECM test and bivariate GARCH-BEKK model. In particular, we considered the symmetric and asymmetric volatility transmissions between the WTI and Brent markets.

By employing the VECM test, we found bi-directional returns transmissions between the WTI and Brent markets. This evidence indicates that the WTI returns have an impact on the Brent returns and vice versa. With regard to symmetric and asymmetric volatility, the empirical results show unidirectional volatility spillover from the WTI market to the Brent market, indicating that information is transmitted from the WTI market to the Brent market but that a reverse direction is impossible. More importantly, bad news in the WTI market seems to increase the volatility of the Brent market more sharply than do good shocks in the WTI market. Thus, these findings indicate that the WTI market appears to play a more important role in influencing the volatility of the Brent market.

These findings are of practical importance to crude oil market participants and may be useful in making optimal portfolio allocation decisions and developing hedging strategies between the two crude oil markets. In the cross-market hedging demand, falling WTI prices induce active hedgers to shift funds from the WTI market to the Brent market. Thus, bad news in the WTI market will increase volatility changes in the Brent market. 


\section{[References]}

1. Aloui, C. and R. Jammazi, "The Effects of Crude Oil Shocks on Stock Market Shifts Behaviour: A Regime Switching Approach,” Energy Economics, Vol. 31, 2009, pp. 789-799.

2. Bekiros, S. D. and C. G. H. Diks, "The Relationship between Crude Oil Spot and Futures Prices: Cointegration, Linear and Nonlinear Causality," Energy Economics, Vol. 30, 2008, pp. 2673-2685.

3. Belloumi, M., "Energy Consumption and GDP in Tunisia: Cointegration and Causality Analysis,” Energy Policy, Vol. 37, 2009, pp. 2745-2753.

4. Chiou, J.-S. and Y.-H. Lee, "Jump Dynamics and Volatility: Oil and the Stock Markets," Energy, Vol. 34, 2009, pp. 788-796.

5. Engle, R. F. and K. F. Kroner, "Multivariate Simultaneous Generalized ARCH," Econometric Theory, Vol. 11, 1995, pp. 122-150.

6. and V. K. Ng, "Measuring and Testing the Impact of News on Volatility," Journal of Finance, Vol. 48, 1993, pp. 1749-1778.

7. Ewing, B. T., F. Malik and O. Ozfidan, "Volatility Transmission in the Oil and Natural Gas Markets,” Energy Economics, Vol. 24, 2002, pp. 525-538.

8. Glosten, L. R., R. Jagannathan and D. E. Runkle, "On the Relation between the Expected Value and the Volatility of the Nominal Excess Return on Stocks," Journal of Finance, Vol. 48, 1993, pp. 1779-1801.

9. Hamilton, J. D. and A. M. Herrera, "Comment: Oil Shocks and Aggregate Macroeconomic Behavior: The Role of Monetary Policy,” Journal of Money, Credit and Banking, Vol. 36, 2004, pp. 265-286.

10. Hooker, M. A., "Are Oil Shocks Inflationary? Asymmetric and Nonlinear Specification versus Changes in Regime," Journal of Money, Credit and Banking, Vol. 34, 2002, pp. $540-561$.

11. Johansen, S., "Estimation and Hypothesis Testing of Cointegration Vectors in Gaussian Vector Autoregressive Models," Econometrica, Vol. 59, 1991, pp. 1551-1580.

12. Kang, S. H. and S.-M. Yoon, "Value-at-Risk Models in Crude Oil Markets," Environmental and Resource Economics Review, Vol. 16, 2007, 947-978. 
13. Kang, S. H. and S.-M. Yoon, "Long Memory and Cointegration in Crude Oil Market Dynamics," Environmental and Resource Economics Review, Vol. 19, 2010, pp. 485-508.

14. Kaufmann, R. K. and B. Ullman, "Oil Prices, Speculation, and Fundamentals: Interpreting Causal Relations among Spot and Futures Prices," Energy Economics, Vol. 31, 2009, pp. 550-558.

15. Kim, J. S., E. N. Heo and Y. B. Kim, “A Study on Regionalization in the World Crude Oil Markets Using Cointegration and Causality Analysis," Environmental and Resource Economics Review, Vol. 16, 2007, pp. 213-239.

16. Kroner, K. F. and V. K. Ng, "Modeling Asymmetric Comovements of Asset Returns," Review of Financial Studies, Vol. 11, 1998, pp. 817-844.

17. Lee, B. R., K. Lee and R. A. Ratti, "Monetary Policy, Oil Price Shocks, and the Japanese Economy." Japan and the World Economy, Vol. 13, 2001, pp. 321-349.

18. MacKinnon, J. G., "Critical Values for Cointegration Tests," In R. F. Engle and C. W. J. Granger, eds., Long-Run Economic Relationships: Readings in Cointegration, New York: Oxford University Press, 1991, pp. 266-276.

19. Malik, F. and S. Hammoudeh, "Shock and Volatility Transmission in the Oil, US and Gulf Equity Markets," International Review of Economics \& Finance, Vol. 16, 2007, pp. 357-368.

20. Mork, K., "Business Cycles and the Oil Market," Energy Journal, Vol. 15, 1994, pp. $15-38$.

21. Osterwald-Lenum, M., "A Note with Quantiles of the Asymptotic Distribution of the Maximum Likelihood Cointegration Rank Test Statistics," Oxford Bulletin of Economics and Statistics, Vol. 54, 1992, pp. 461-471.

22. Rafiq, S., R. Salim and H. Bloch, "Impact of Crude Oil Price Volatility on Economic Activities: An Empirical Investigation in the Thai Economy," Resources Policy, Vol. 34, 2009, pp. 121-132.

23. Ross, S. A., "Information and Volatility: The No-Arbitrage Martingale Approach to Timing and Resolution Irrelevancy," Journal of Finance, Vol. 44, 1989, pp. 1-17.

24. Sadorsky, P., "Oil Price Shocks and Stock Market Activity," Energy Economics, Vol. 21, 1999, pp. 449-469. 
Information Transmission of Volatility between WTI and Brent Crude Oil Markets

25 . , "The Empirical Relationship between Energy Futures Prices and Exchange Rates," Energy Economics, Vol. 22, 2000, pp. 253-266.

26. , "Risk Factors in Stock Returns of Canadian Oil and Gas Companies," Energy Economics, Vol. 23, 2001, pp. 17-28.

27. , "Correlations and Volatility Spillovers between Oil Prices and the Stock Prices of Clean Energy and Technology Companies," Energy Economics, Vol. 34, 2012, pp. 248-255.

28. Seo, J. Y., "International Oil Price Shock to the Prices of Korean Government \& Public Bonds" Journal of Industrial Economics and Business, Vol. 22, 2009, pp. 477-494.

29. Zhang, Y.-J., Y. Fan, H.-T. Tsai and Y.-M. Wei, "Spillover Effect of US Dollar Exchange Rate on Oil Prices," Journal of Policy Modeling, Vol. 30, 2008, pp. 973-991. 